\title{
Tricuspidization of incompetent bicuspid aortic valve
}

\author{
Kohei Kawazoe, MD, Hiroshi Izumoto, MD, Jyunichi Tsuboi, MD, and
}

Jyunichi Koizumi, MD, Iwate, Japan

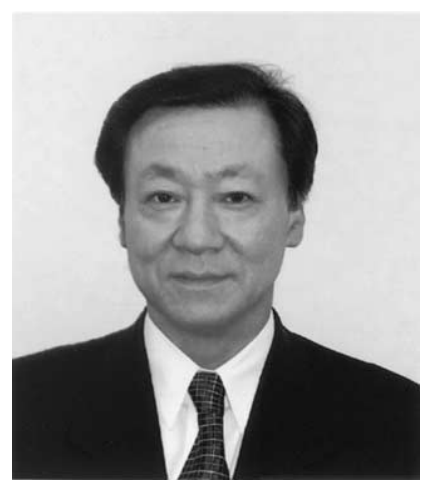

Dr Kawazoe

T

he conventional surgical therapy for severe aortic regurgitation (AR) from congenital bicuspid valve has been aortic valve replacement. In the past decade, there has been a revival of aortic valve repair in this subset of patients. ${ }^{1,2}$ We developed a new technique of tricuspidization to repair incompetent bicuspid valve. Because we believe that this technique is new and novel, we report the surgical technique along with intraoperative echocardiographic findings.

\section{Clinical Summary and Repair}

A 24-year-old man was referred to our hospital for surgical repair of severely incompetent aortic valve caused by congenital bicuspid valve. He had been medically followed by a local pediatrician since the age of 10 years because of AR. Over the course, aortic root dilatation developed, the AR was aggravated to grade IV/IV, and episodes of premature ventricular contractions began to occur. At admission, he was in New York Heart Association functional class II, and the echocardiogram showed dilated root (annulus diameter $=34 \mathrm{~mm}$, Valsalva sinus diameter $=50 \mathrm{~mm}$, sinotubular junction diameter $=43 \mathrm{~mm}$ ) and grade IV AR. End-diastolic and end-systolic left ventriclular diameters were $68 \mathrm{~mm}$ and $38 \mathrm{~mm}$, respectively, and left ventricle ejection fraction was $74 \%$. The leaflet with a raphe was prolapsing. On the basis of these findings, we decided to perform the Yacoub remodeling technique in combination with aortic valve repair.

Aortic valve repair was performed in combination with Yacoub's remodeling by use of a $28-\mathrm{mm}$ vascular graft. Because the aortic annulus was dilated, a subvalvular circular annuloplasty,

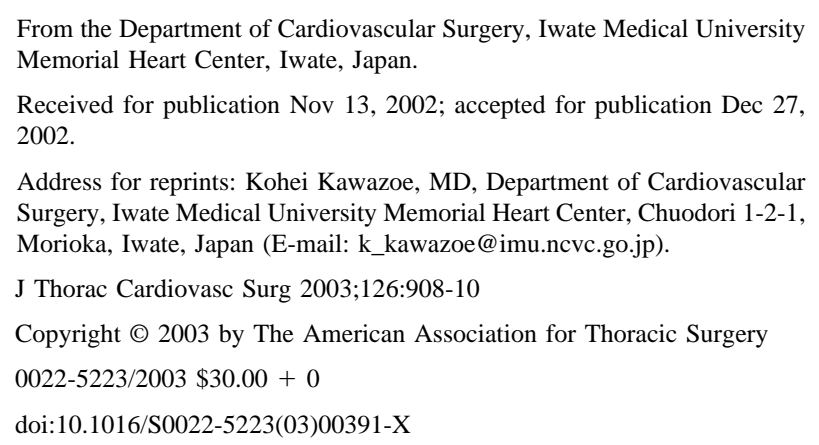

which we have reported elsewhere, ${ }^{3}$ was performed to securely reduce the annulus size. The tricuspidization was performed with the use of 5-0 polytetrafluoroethylene suture (Gore-Tex; W. L. Gore \& Associates, Inc, Flagstaff, Ariz). The fused commissure (raphe) between the right and left cusps was partially cut back. In the middle of the prolapsing leaflet margin, horizontal mattress suture of CV-5 was placed with a small pledget (Figure 1, $A$ ). The ends of the sutures were passed outside the aorta at the level of commissural edge corresponding to the raphe insertion (Figure 1, $A$ ). and held with a tourniquet. Yacoub's remodeling procedure was then started. The aortic root was replaced by a $28-\mathrm{mm}$ vascular graft, and the coronary buttons were transferred to the graft. An occlusion balloon was placed in the graft, and the proximal suture line leak and valve competence were both checked. The distal graft suture was completed, and the patient was weaned from cardiopulmonary bypass. Under the transesophageal echocardiography, the CV-5 suture length was adjusted in accordance with on-line transesophageal echocardiography findings, and the sutures were tied.

The patient's postoperative course was uneventful. Echocardiography at discharge demonstrated decreased left ventricular size (end-systolic diameter $=34 \mathrm{~mm}$, end-diastolic diameter $=46 \mathrm{~mm}$ ) with trivial AR. Aortic root dimensions were normalized postoperatively. Annulus, maximal sinus, and sinotubular juction diameters were $2.3 \mathrm{~cm}, 3.3 \mathrm{~cm}$, and $2.6 \mathrm{~cm}$, respectively. Six months after the operation, the patient has returned to his normal activity and is in New York Heart Association class I status. Figures 2 and 3 show preoperative and postoperative echocardiographic findings. Figure 4 shows postoperative Doppler echocardiographic findings (long-axis view). The aortic valve regurgitation is reported as trivial, and the valve has been competent during the follow-up period.

\section{Discussion}

Bicuspid aortic valve is one of the main causes of AR, and this disease affects people at a young age. Aortic valve repair may be beneficial in young patients to avoid life-long anticoagulation or complications of mechanical heart valve. A limited number of groups have reported intermediate or long-term results of aortic valve repair for bicuspid valve. ${ }^{1,2,4}$ 

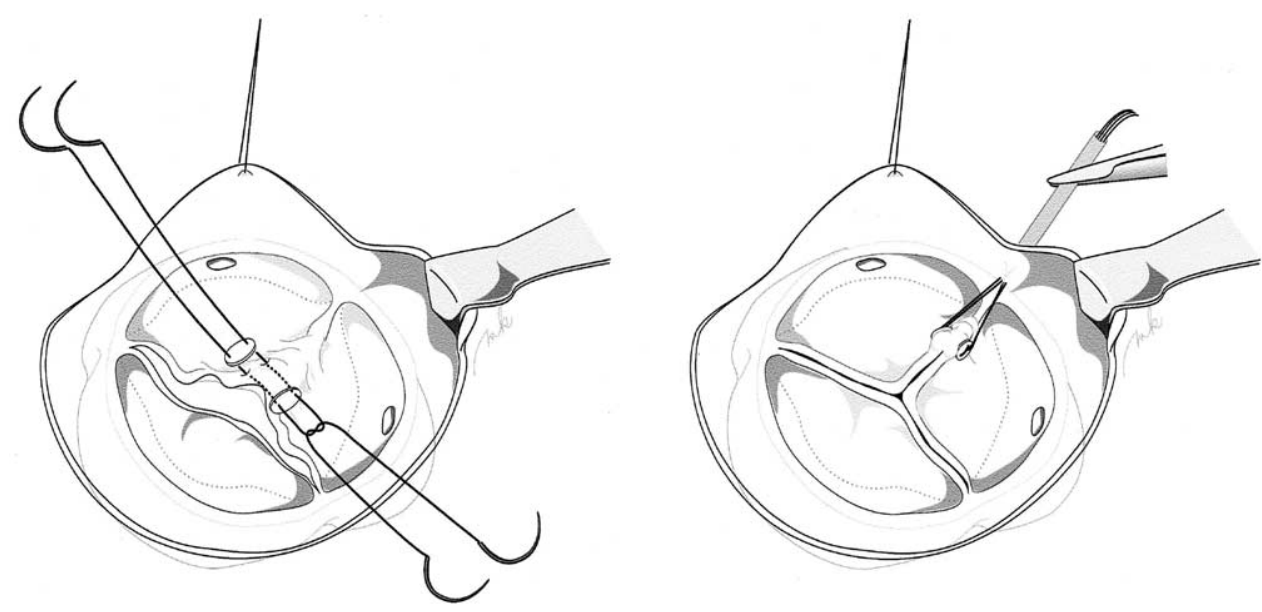

Figure 1. Schematic demonstration of the procedure.
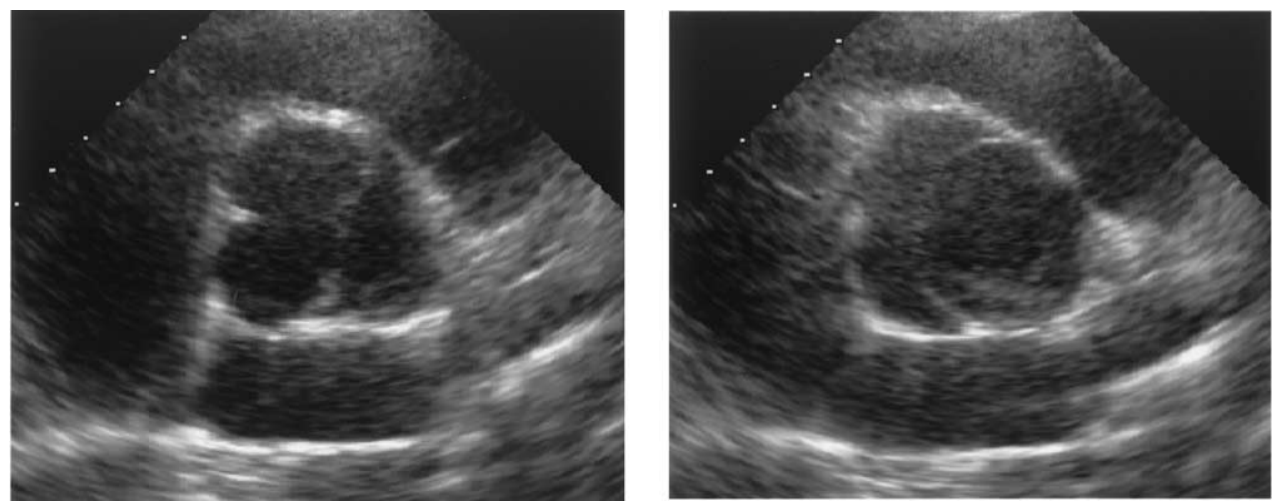

Figure 2. Preoperative transthoracic echocardiogram. At valve closure (left); at valve opening (right).
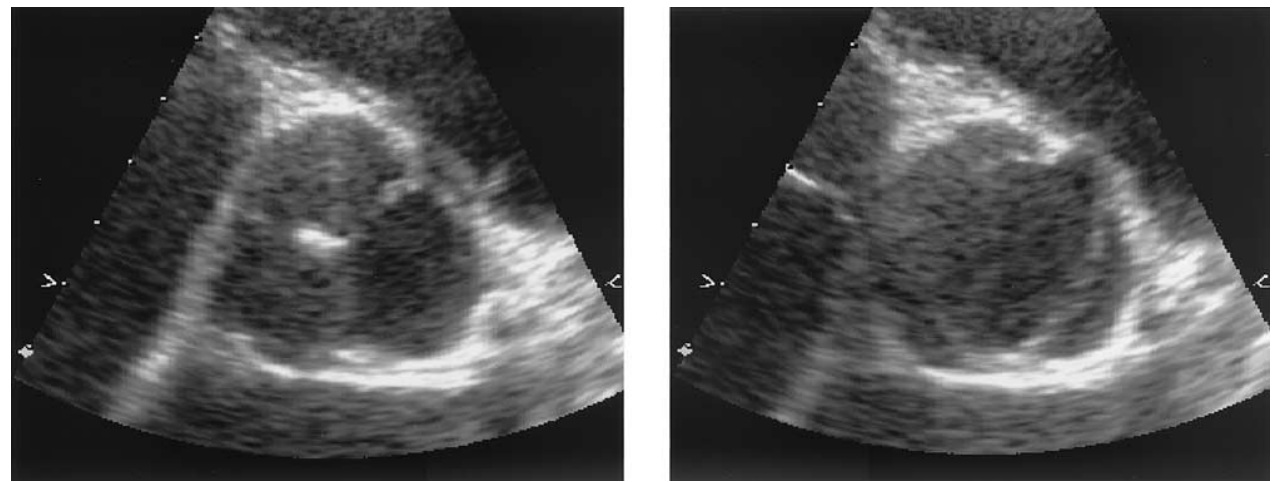

Figure 3. Transthoracic echocardiogram 6 months after surgery. At valve closure (left); at valve opening (right).

According to analysis, most reported surgical techniques are related to procedures on the leaflet (leaflet plication or triangular resection) or on the commissure (commissuroplasty). In this technique, a tricuspid valve is formed, thereby creating a new commissure. To the best of our knowledge, there has not been any report on the tricuspidization procedure. The idea of tricuspidiza- tion is new, and this technique may have an advantage over conventional bicuspid valve repairs. With the use of this technique, we may be able to avoid or minimize the risk of postoperative restricted cusp motion, which has been one of the drawbacks of the repair. In conventional repair, the annulus is plicated with subcommissural annuloplasty or commissuroplasty. In this setting, a 

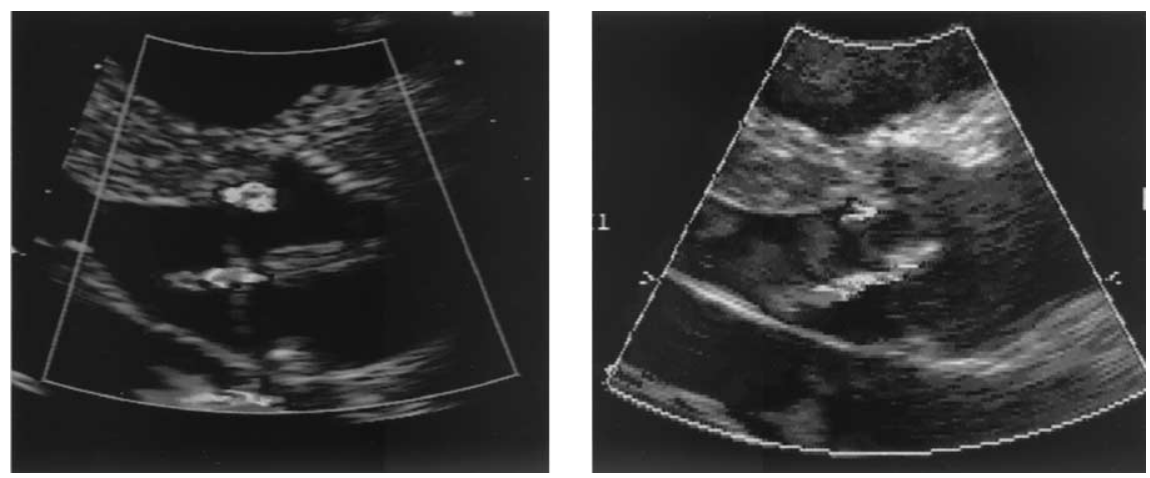

Figure 4. Postoperative Doppler echocardiogram. At hospital discharge (left); 6 months after surgery (right).

triangular resection or leaflet plication alone may render the cusp motion restricted. Therefore, the repaired valve with restricted cusp motion may undergo undue stress. By making the valve tricuspid, the valve moves more physiologically, its opening area may become larger, and the stress on the valve may be minimized. Casselman and colleagues ${ }^{2}$ reported 12 reoperations among 94 patients after repair of bicuspid aortic valve. Most of their reoperations were performed because of suture dehiscence of the triangular resection. In view of long-term durability, we anticipate that this new technique will prove superior to the conventional technique because the stress on the repaired valve is lessened. However, long-term durability after the repair remains to be determined.

\section{References}

1. Haydar HS, He GW, Hovaguimian H, McIrvin DM, King DH, Starr A. Valve repair for aortic insufficiency: surgical classification and techniques. Eur J Cardiothorac Surg. 1997;11:258-65.

2. Casselman FP, Gillinov AM, Akhrass R, Kasirajan V, Blackstone EH, Cosgrove DM. Intermediate-term durability of bicuspid aortic valve repair for prolapsing leaflet. Eur J Cardiothorac Surg. 1999;15:302-8.

3. Izumoto H, Kawazoe K, Kawase T, Kim H. Subvalvular circular annuloplasty as a component of aortic valve repair. J Heart Valve Dis. 2002;11:383-5.

4. Izumoto H, Kawazoe K, Ishibashi K, Kin H, Kawase T, Nakajima T, et al. Aortic valve repair in dominant aortic regurgitation. Jpn J Thorac Cardiovasc Surg. 2001;49:355-9.

\title{
Drowned donor lung for bilateral lung transplantation
}

\author{
C. J. McNamee, MD, ${ }^{a}$ D. L. Modry, MD, ${ }^{b}$ D. Lien, MD, ${ }^{b}$ and A. Alan Conlan, MD, ${ }^{a}$ \\ Worcester, Mass, and Edmonton, Alberta, Canada
}

ubmersion accidents may result in three outcomes: death by drowning, secondary drowning death (rescue of a victim with vitals signs who later dies of complications), or near drowning of a victim who survives after being

\footnotetext{
From the Department of Surgery, ${ }^{a}$ University of Massachusetts Medica School, Worcester, Mass, and the Departments of Surgery and Medicine, ${ }^{b}$ University of Alberta, Edmonton, Alberta, Canada.

Received for publication Dec 26, 2002; accepted for publication Feb 19, 2003.

Address for reprints: C. J. McNamee, MD, 67 Belmont St, Worcester, MA 01605 (E-mail: mcnameec@ummhc.org).

J Thorac Cardiovasc Surg 2003;126:910-2

Copyright $\odot 2003$ by The American Association for Thoracic Surgery $0022-5223 / 2003 \$ 30.00+0$

doi:10.1016/S0022-5223(03)00370-2
}

rescued. It is estimated that worldwide there are 140,000 to 150,000 yearly deaths by drowning, with 6000 to 8000 of these deaths occurring in the United States. ${ }^{1,2}$ Drowning causes global ischemia from hypoxia, and the cause of death at the scene is probably cardiac dysfunction; in secondary drowning deaths, however, the final common pathway is brain death from cerebral hypoxia. ${ }^{1-4}$

In $10 \%$ to $15 \%$ of secondary drowning victims, dry drowning (no aspiration of water into the lungs) occurs; death in this situation is caused by acute laryngospasm leading to profound obstructive asphyxia. ${ }^{1-3}$ It would seem unreasonable to consider lungs for transplantation from a victim of drowning; because of organ shortages, however, there are now efforts to consider marginal lungs for transplantation. ${ }^{5,6}$ In our case, we implanted both lungs from a victim of dry drowning into a patient with pulmonary hypertension related to veno-occlusive disease after all criteria for donor lung transplantation acceptability were met. An excellent result at 35 months of follow-up was achieved. 